\title{
Intramyocardic needle in a man with auto-aggressive behavior
}

\author{
Giraldo Fabián $^{1 *}$, Hernández Guillermo ${ }^{1}$ and Hernández Jessica ${ }^{2}$ \\ ${ }^{1}$ Instituto del Corazón de Bucaramanga, Colombia \\ ${ }^{2}$ Clínica Foscal Internacional, Colombia
}

\begin{abstract}
Inracardiac foreign bodies and its complications represent a big challenge to surgeon for that initial symptoms are unspecific and it is difficult to exactly localize the foreign body due to permanent movement of the heart. We present a case of successful removal of an intracardiac needle without cardiopulmonary bypass (CPB). Under the guidance of transesophageal echocardiography (TEE), a sternotomy was performed and the needle was located and removed. The patient was discharged from hospital 5 day after the procedure without complications.
\end{abstract}

\section{Introduction}

Self-inflicted intracardiac foreign bodies by patients with autoaggressive behavior are a rare occurrence. The migration of such objects into the heart chambers can cause cardiac complications include pericarditis, infective endocarditis, cardiac tamponade, arrhythmias, ventricular perforation and death [1-4]. There is no consensus for the treatment of a cardiac foreign body [5-7], some authors suggest surgical removal of a foreign body over conservative management to prevent further damage to the heart [8-12]. We report a case of a selfinflicted injury to the heart by a needle, presenting with nonspecific chest pain and subsequently complicating with cardiac tamponade secondary to right ventricle perforation, this needle was successfully extracted 4 months after its insertion.

\section{Case Report}

32-year-old male patient with a congenital neural hypoacusia, and major language impairing. The patient was taken to the emergency room by her wife. On admission, the patient was complaining of dyspnea, chest pain and palpitations.

The patient had a history of major depressive disorder and suicide attempt, with multiple self-inflicted episodes. There was also a history of chest abscess 4 months ago, apparently by needle injury to the left anterior wall of his chest (suicidal attempt).

Physical examination revealed mild respiratory distress, diaphoresis, cutaneous pallor, abscess in left chest and systemic inflammatory response signs. During work-up the patient presented multiple seizures (no focal deficit); lumbar puncture and brain scan were normal. Electrocardiogram was normal. A chest X-ray showed a linear metallic density within the cardiac silhouette (Figure 1). Thorax CT scan showed pericardial thickening, and a linear metallic density in right ventricle (Figure 2). Trans-thoracic echocardiography revealed signs of constrictive pericarditis and pericardial effusion. Shortly after, the patient revealed clinical signs of pericardial tamponade requiring ultrasound-guided pericardiocentesis and obtaining $280 \mathrm{ml}$ of blood. With these findings surgical removal of foreign body was decided.
A full sternotomy approach revealed severe pericardial thickening, multiple blood clots in pericardial space and a normal appearing heart. Intraoperative trans-esophageal echocardiography (TEE) was used to help locate the foreign body which was determined to be in the right ventricle (Figure 3). In order to accurately locate the needle, the right ventricle was gently pressed against the surgeon's fingers then a squeeze motion was performed to extract the needle uneventfully via the inferior wall of the heart (Figure 4). TEE revealed no significant changes in cardiac function after the procedure. During hospitalization

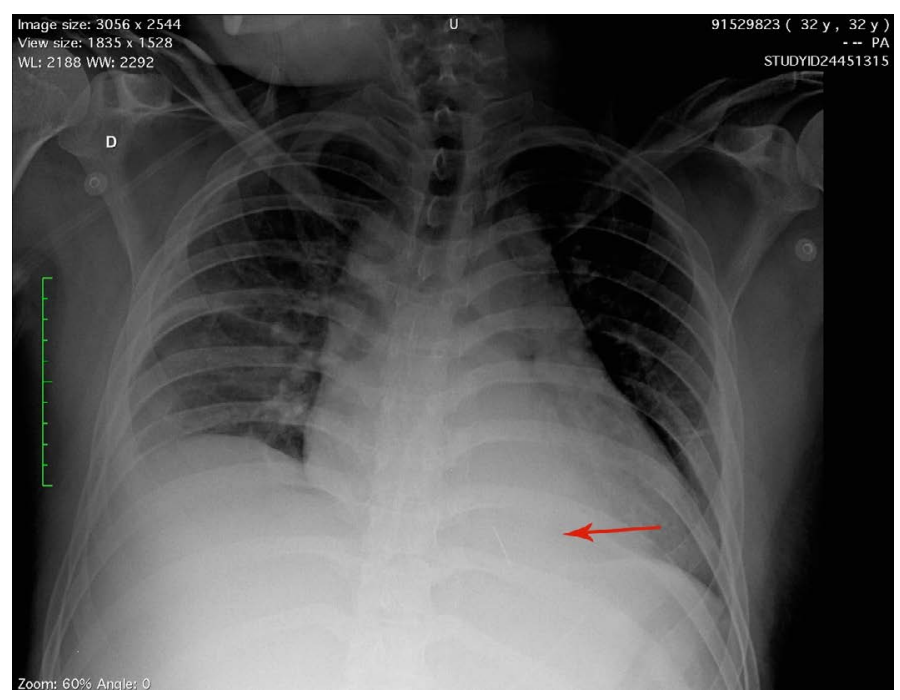

Figure 1. Chest X-ray revealed a needle in the chest

${ }^{\star}$ Correspondence to: Giraldo Fabián, Instituto del corazón de Bucaramanga. Carrera. 28 \# 40-11, Bucaramanga Colombia, Tel: 300619 1819; E-mail: fabiangiraldomd@gmail.com

Key words: foreign body, intracardiac needle, transesophageal echocardiography, computed tomography, cardiopulmonary bypass

Received: June 05, 2018; Accepted: June 12, 2018; Published: June 20, 2018 


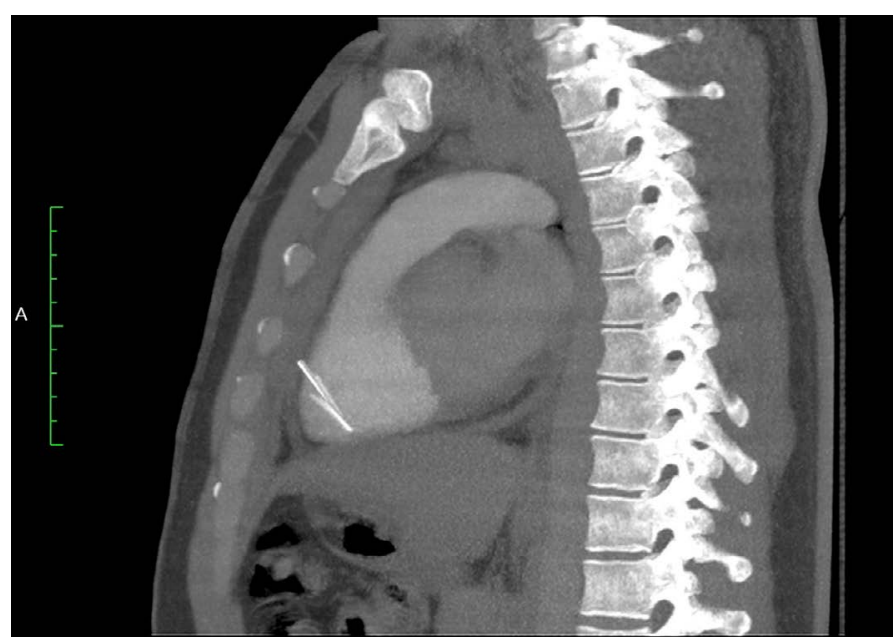

Figure 2. CT showing the needle in the right ventricle

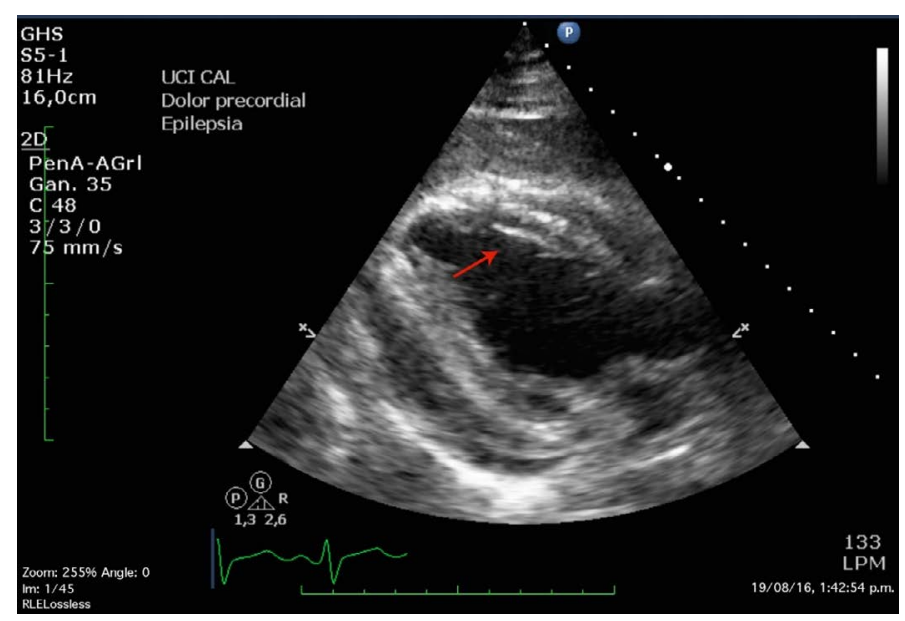

Figure 3. TEE showed the needle in the right ventricle, which help determine exact localization of foreign body

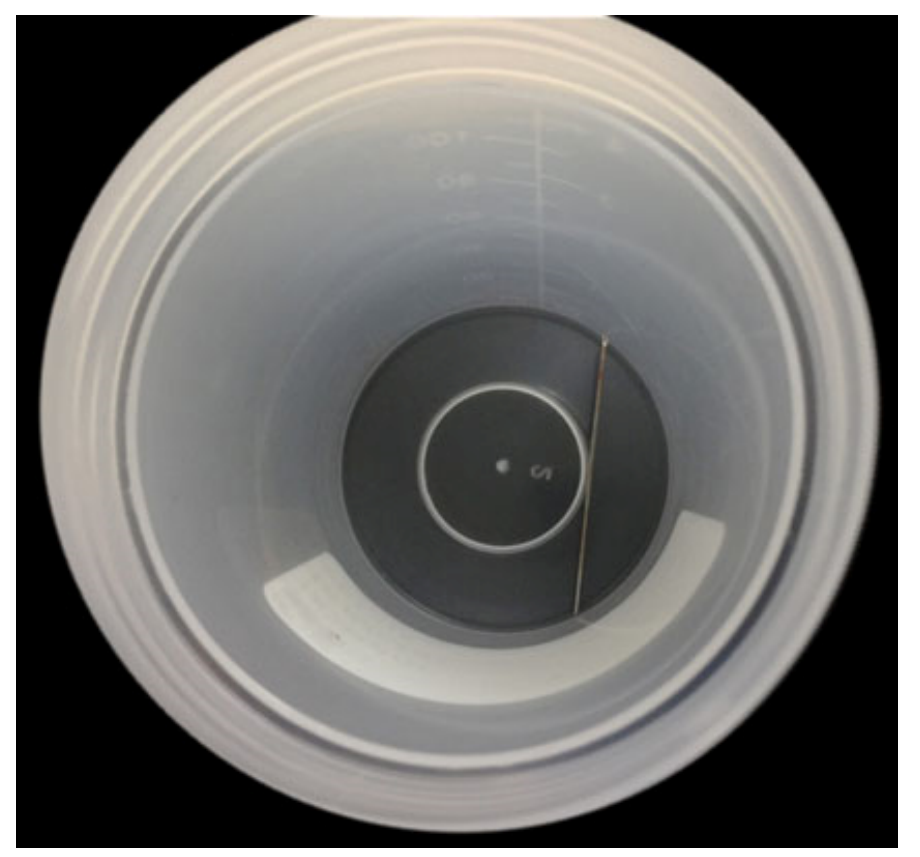

Figure 4. Hypodermic needle extracted from right ventricle the patient received psychiatric evaluation and was discharged 5 days after the procedure. Then he was admitted in a psychiatric clinic to continue management.

\section{Discussion}

Heart lesions caused by introduction of foreign bodies in the thorax by patients with auto- aggressive behavior are extremely rare [1-5], but these injuries may occur usually in patients that suffer from psychiatric disorders in association with depressive symptoms and suicide attempts [6].

This is a rare case of penetrating cardiac injury caused by a hypodermic needle. Is well known that needles can easily and rapidly migrate through tissues and may lead to life-threatening complications [7].

Such patients can be completely asymptomatic [4]. However, this case demonstrates how quickly an asymptomatic patient can deteriorate. Acute pericarditis is the usual presenting feature in these cases but hemothorax, cardiac tamponade, and pneumothorax have also been described. Infective endocarditis may develop in longstanding cases. The most common symptoms are dyspnea and chest pain $[8,9]$.

Routine electrocardiographic examination does not show any specific finding. CT-scan, trans-thoracic and trans-oesophageal echocardiography have been used preoperatively to locate the exact position of a foreign body and its correlation with the surrounding tissues [10].

Given the needle's tendency to migrate, several authors recommend intraoperative epicardial ultrasound or fluoroscopy, which are useful to locate the needle's position in the heart and the presence of intracavitary thrombus. Unfortunately, these diagnostic tools are not available in every operative room [11].

There are no guidelines addressing the treatment of cardiac foreign bodies. Several case reports raise the question if all foreign bodies should be removed [4-7]; different series suggests that immediate surgical removal of a foreign body is preferred over conservative management to prevent further damage to the heart [8-12]. In our opinion the definitive treatment must be tailored case by case according to symptoms and associated risk factors. The presence of symptoms is an indication for surgery, especially with the presence of cardiac tamponade, recurrent pericardial effusion, pericarditis, arrhythmia or embolization. Surgical approach depends on the localization of the foreign body; sternotomy is recommended when pericardiectomy is planned $[13,14]$, cardiopulmonary bypass is used to help remove intramyocardic needles $[10,11,15]$. To the best of our knowledge, we report here the second case of intramyocardic needle removal without $\mathrm{CPB}$ [16], the decision to performing sternotomy was based mainly for the presence of pericarditis. TEE is a vital tool that help localize the needle, especially in the right and posterior regions of the heart [17]. Furthermore, TEE help assess preoperatively and postoperatively the function and structures changes in the heart.

\section{References}

1. Gungor H, Duygu H, Yildiz BS, Gul I, Zoghi M, et al. (2010) A remnant sewing needle in the right ventricle as a cause of chest pain. Clin Cardiol 33: E23-25. [Crossref]

2. Talwar S, Subramaniam KG, Subramanian A, Kothari SS, Kumar AS (2006) Sewing needle in the heart. Asian Cardiovasc Thorac Ann 14: 63-65. [Crossref]

3. Borracci RA, Milani AP, Ahuad Guerrero RA (2005) [Intracardiac sewing needle in a women with autoaggressive behavior]. Rev Esp Cardiol 58: 456-457. [Crossref] 
4. Perrotta S, Perrotta A, Lentini S (2010) In patients with cardiac injuries caused by sewing needles is the surgical approach the recommended treatment? Interact Cardiovasc Thorac Surg 10: 783-792. [Crossref]

5. Actis Dato GM, Arslanian A, Di Marzio P, Filosso PL, Ruffini E (2003) Posttraumatic and iatrogenic foreign bodies in the heart: report of fourteen cases and review of the literature. J Thorac Cardiovasc Surg 126: 408-414. [Crossref]

6. 6. Sayin AG, Besirli K, Arslan C, Cantu rk E (2002) A case of intramyocardial sewing needle extracted without stopping the heart. Injury 33: 276-277. [Crossref]

7. Nishida S, Tomita S, Watanabe G, Yasuda T, Iino K, et al. (2005) Intramyocardial foreign body: sewing needle with the uncommon clinical feature of constrictive pericarditis. Jpn J Thorac Cardiovasc Surg 53: 598-600. [Crossref]

8. Qian H, Song H, Li Y, Jiang C (2015) Removal of metallic foreign body in heart by minimally invasive procedure under the guidance of transesophageal echocardiography and transthoracic echocardiogram. J Thorac Dis 7: E560-E563. [Crossref]

9. Wang X, Zhao X, Du D, Xiang X (2012) Management of metallic foreign bodies in the heart. J Card Surg 27: 704-706. [Crossref]

10. Datta G, Sarkar A, Mukherjee D (2011) A foreign body in the heart. Arch Cardiovasc Dis 104: 684-685. [Crossref]
11. Mandegar MH, Ali Yousefnia M, Rayatzadeh H, Roshanali F (2006) Intramyocardial sewing needle extracted one year after insertion. Interact Cardiovasc Thorac Surg 5: 742-3. [Crossref]

12. Inoue T, Iemura J, Saga T (2003) Delayed cardiac tamponade caused by self-inserted needles. Can J Cardiol 19: 306-308. [Crossref]

13. Van Way CW 3rd (1989) Intrathoracic and intravascular migratory foreign bodies. Surg Clin North Am 69: 125-133. [Crossref]

14. Culliford AT (1985) Surgery for chronic constrictive pericarditis. In: Roberts AJ (Ed.), Difficult problems in adult cardiac surgery. Chicago: Year Book Medical Publishers; 317-24.

15. Liu H, Juan YH, Wang Q, Lin YC, Liang C, et al. (2014) Foreign body venous transmigration to the heart. QJM 107: 743-745. [Crossref]

16. Qian H, Song H, Li Y, Jiang C (2015) Removal of metallic foreign body in heart by minimally invasive procedure under the guidance of transesophageal echocardiography and transthoracic echocardiogram. J Thorac Dis 7: E560-3. [Crossref]

17. Aguirre MA, Trousdale D, John A, Greilich PE (2008) The use of transesophageal echocardiography in determining the structural and functional impact of traumatic intracardiac foreign bodies. Anesth Analg 107: 1155-7. [Crossref]

Copyright: $@ 2018$ Fabián G. This is an open-access article distributed under the terms of the Creative Commons Attribution License, which permits unrestricted use, distribution, and reproduction in any medium, provided the original author and source are credited. 